\title{
Knee Osteoarthritis and Running: Is there any Evidence for Association?
}

\section{Manoj Kumar Nair}

Dubai Physiotherapy and Rehabilitation Centre, Dubai Health Authority, Dubai, United Arab Emirates

"Corresponding author: Manoj Kumar Nair, Physiatrist, Dubai Physiotherapy and Rehabilitation Centre, Dubai Health Authority, Dubai, United Arab Emirates, Tel: +971502024435; E-mail: drmanupv@gmail.com

Received date: October 17, 2017; Accepted date: November 06, 2017; Published date: November 10, 2017

Copyright: ( 2017 Nair MK. This is an open-access article distributed under the terms of the Creative Commons Attribution License, which permits unrestricted use, distribution, and reproduction in any medium, provided the original author and source are credited.

\begin{abstract}
The knee is the most common lower limb joint affected with Osteoarthritis (OA), which is a debilitating illness. The relationship between $\mathrm{OA}$ knee and running is not clear-cut, yet they are always associated with one another. The multitude of people suffering from lifestyle diseases is approaching epidemic proportions and Governments have to spend millions of dollars to manage these disorders. This has forced authorities to think about primary prevention rather than managing them after their onset. Slowly and steadily, the awareness about physical activity is increasing among the public. Due to this, there has been a surge in the number of people participating in activities for health reasons. The number of people taking part in running has also increased significantly. Many people resort to jogging and running because it is cost effective and convenient when compared to other types of exercises which need equipment or memberships. However, in addition to this, the concerns of damage to the knee joint have attracted the attention of clinicians and researchers. The common notion is that running damages the knees. Recent studies show that this concern is misplaced. The existing scientific evidence could not establish a link between the two, except in joints with a history of previous injury. Interestingly, results of some studies show that the chances of undergoing surgery for $\mathrm{OA}$ are less in runners. This article reviews the relevance of high-quality literature that looks at the link between running and the development of knee osteoarthritis.
\end{abstract}

Keywords: Knee; Osteoarthritis; Running; Marathon runners

\section{Introduction}

Participation in sports and physical activity provides physical, mental, social and economic benefits to both the individual and the society [1]. Among the different types of physical activities, walking, jogging and running are the most popular ones. Since the latter part of the 20th century, running has become a popular sport around the world. People of all spectra take part in different running events, from recreational runners to professionals doing ultramarathon events. In the last few decades, the number of people finishing a marathon has increased significantly. The main reasons for the increasing popularity of running is its accessibility and low participation cost. The requirements for running are minimal- a safe place to run, a pair of shoes (not essential, as running bare foot is gaining momentum in different parts of the world) and a passion to run!

There are multiple health benefits attributed to running - it creates a positive mood, improves physical fitness, reduces obesity, cardiovascular disorders, other metabolic dysfunctions, and many other chronic health problems.

When we talk about running the first question that pops up in one's mind is, "Does it damage our knees?" There are serious concerns about the relationship of running and the development of knee Osteoarthritis. Therefore, it is crucial for us to look into the available scientific evidence behind this relationship.

\section{Osteoarthritis- Its Prevalence and Predisposing Factors}

Osteoarthritis (OA) is the most common joint disorder throughout the world [2]. It is defined as "a heterogeneous group of conditions that lead to joint symptoms and signs associated with defective articular cartilage and changes to the underlying bone and joint margins" [3]. The diagnosis of Osteoarthritis of the knee can be clinical, radiological or both. Radiological investigations are done to determine its severity and grading (Kellgren \& Lawrence; KL scoring) is done from 0 to 4 . In the US alone, there are about 9 million adults estimated to have clinically diagnosed OA knee [4]. However, more often than not, the radiological evidence does not correlate with clinical findings. According to the Framingham study, radiographic knee OA occurs in at least $33 \%$ of population above 60 yrs. of age, but only $10-15 \%$ are symptomatic [5].

There are a number of risk factors that lead to the development of OA- obesity, occupational activity, joint injury, age, sex, genetics and ethnicity- to name some. The estimated lifetime risk for knee OA is approximately $40 \%$ in men and $47 \%$ in women. The risks are higher among individuals who are obese [6]. The different variables responsible for the susceptibility of a joint to develop osteoarthritis are joint shape, joint stability, muscle strength, body mass, response of the tissues to exercise and genetically determined composition/structure of articular cartilage [7]. Primary factors leading to the development of OA knee are muscle dysfunction and weakness as part of injury, inadequate rehabilitation, overuse, and inactivity [8]. The muscles are the predominant shock absorbers in normal knees. The articular cartilage does not absorb the remaining force, but redistributes it to the underlying bone. Even during vigorous exercise, the knees are protected if it had undergone adaptation and regeneration through muscle training.

\section{Running and Osteoarthritis of Knee-Evidences in Literature}

It is difficult to establish the relationship between running and knee OA through clinical studies as there are different variables involved in 
association and causation. Some of the variables are long time interval between exposure and outcome, variability in running pattern of the individuals, history of injuries and innate predisposing factors.

High quality studies evaluated runners for a certain number of years to see the effect of running on knees. These studies found that trained marathon runners tend to have normal post-race magnetic resonance imaging findings, whereas beginners show abnormalities after running the same distance [9].

There is little to no correlation between $\mathrm{X}$ ray findings and the symptoms of OA. The degenerative process advances with aging irrespective of the activity level. Even the best prospective studies could not establish increase in rate of progression of OA in active people compared with non-exercisers [10]. Many of these studies did follow ups for very long periods of time, such as the Stanford University trial, which had 18 years of follow up [11].

Exercise could not demonstrate any detrimental effect even on people with hip or knee osteoarthritis. Studies comparing risks and benefits of high versus low-intensity physical activity were also nonconclusive [12].

Running has a low participation cost and can be performed almost anywhere, which makes it an ideal activity to combat the negative effects of physical inactivity and obesity [13].

Data suggests that long-distance running may not be associated with increased progression of knee OA in the absence of knee injury, obesity, proprioceptive deficit, or poor muscle tone [11]. 45 long distance runners were compared with 53 controls by radiological evaluation (X-ray knee KL scoring) for a period of 18 years. By the end of the study, researchers could not find increased prevalence or deterioration of OA in runners compared to controls [11].

There is mounting evidence showing that increase in level of exercise lowers the musculoskeletal disability, pain and improvement in functional capacity $[14,15]$. The Stanford University Runner's study, which lasted for about 21 years, showed that morbidity and mortality were less among runners compared to the controls [16].

In the Framingham study, the effects of recreational physical activity on development of knee OA were studied on 1279 subjects, and it confirmed that recreational or higher activity than peers does not increase the risk of OA knee or results in reduction of joint space. The study also could not find detrimental effect of activity even in people with high BMI (mean BMI $>30 \mathrm{~kg} / \mathrm{m}$ ) [17].

In a study by Williams et al following up 74752 runners for a period of 7.1 years, found that 2004 runners $(2.6 \%)$ developed knee OA. The same study followed up 14,625 walkers for a period of 5.7 years and found that 695 walkers (4.75\%) developed knee OA. According to their findings, the proportion of people developing $\mathrm{OA}$ was higher in walkers than in runners. They also found that those running at an intensity of 1.8 to $3.6 \mathrm{MET}-\mathrm{h} /$ day had $18 \%$ reduced chances of knee OA than people who ran $<1.8 \mathrm{MET}-\mathrm{h} /$ day. This study found that higher baseline BMI was strongly associated with OA knee [18].

In a systematic review and meta-analysis, Tran and associates concluded that there is very low quality evidence to support the increased relationship between sports participation and OA in elite participants [19]. Similarly, findings from the osteoarthritis initiative shows there is no increase in symptomatic knee OA among selfselected runners when compared to non-runners and running is not detrimental in people without OA knee [20]. In their systematic review and meta-analysis, Timmins et al. found that there is not enough evidence to conclude that running is associated with the diagnosis of knee OA. There is no evidence to support the difference in radiographic and other imaging markers between runners and nonrunners. On the contrary, they found that runners had a $50 \%$ reduced odds of undergoing surgery due to OA [21].

\section{Conclusion}

Osteoarthritis $(\mathrm{OA})$ of the knee is a disorder having a multi-factorial etiology. However, running is considered as an activity that causes damage to the cartilage and accelerates the process of degeneration of the knee joint. It is important for the athlete as well as the clinician to know the evidences available in the scientific literature for this hypothesis.

Physical activity has many positive aspects in prevention and management of chronic illness. It is imperative for clinicians to guide patients with evidences due to the ease of running and its popularity around the globe.

There is no evidence for advancing knee $\mathrm{OA}$ in active people who does exercise. This is true in the case of long distant runners. Evidences support the role of exercise in improving musculoskeletal disability, pain and functional capacity.

Many years of follow up of runners could not find any concrete evidence linking running with development of osteoarthritis of knees. Interestingly, running seems to reduce the need of knee replacement by around 50\% compared with non-runners. Previous injury is a strong predictor development of knee osteoarthritis in runners.

\section{References}

1. Saxon L, Finch C, Bass S (1999) Sports Participation, Sports Injuries and Osteoarthritis: Implications for Prevention. Sports Med 28: 123-135.

2. Johnson VL, Hunter DJ (2014) The epidemiology of osteoarthritis. Best Pract Res Clin Rheumatol 28: 5-15.

3. Panush RS, Lane NE (1994) Exercise and the musculoskeletal system. Bailleires Clin Rheum 8: 79-102.

4. Timmins KA, Leech RD, Batt ME, Edwards KL (2017) Running and Knee Osteoarthritis: A Systematic Review and Meta-analysis. Am J Sports Med 45: 1447-1457.

5. Felson DT (2004) An update on the pathogenesis and etiology of osteoarthritis. Radiol Clin North Am 42: 1-9.

6. Lawrence RC, Felson DT, Helmick CG, Arnold LM, Choi H, et al. (2008) Estimates of the prevalence of arthritis and other rheumatic conditions in the United States. Part 2. Arthritis Rheum 58: 26-35.

7. Lane NE (1995) Exercise: a cause of osteoarthritis. J Rheumatol 22: 3-6.

8. Shrier I (2004) Muscle dysfunction versus wear and tear as a cause of exercise related osteoarthritis: an epidemiological update. Br J Sports Med 38: 526-535.

9. Hohmann E, Wörtler K, Imhoff A (2005) Osteoarthritis from longdistance running? [Article in German]. Sportverletz Sportschaden 19: 89-93.

10. Bosomworth NJ (2009) Exercise and knee osteoarthritis: benefit or hazard? Canadian Family Physician 55: 871-878.

11. Chakravarty EF, Hubert HB, Lingala VB, Zatarain E, Fries JF (2008) Long Distance Running and Knee Osteoarthritis. Am J Prev Med 35: 133-138.

12. Regnaux J, Lefevre-Colau M, Trinquart L, Nguyen C, Boutron I, et al. (2015) High-intensity versus low-intensity physical activity or exercise in people with hip or knee osteoarthritis. Cochrane Database Syst Rev 10: CD010203. 
Citation: Nair MK (2017) Knee Osteoarthritis and Running: Is there any Evidence for Association?. J Arthritis 6: 257. doi: 10.4172/2167-7921.1000257

Page 3 of 3

13. Gortmaker S, Swinburn B, Levy D, Carter R, Mabry PL, et al. (2011) Changing the future of obesity: Science, policy, and action. Lancet 378 : 838-847.

14. Wang BW, Ramey DR, Schettler JD, Hubert HB, Fries JF (2002) Postponed development of disability in elderly runners: a 13-year longitudinal study. Arch Intern Med 162: 2285-2294.

15. Lane NE, Bloch DA, Wood PD, Fries JF (1987) Aging, long-distance running, and the development of musculoskeletal disability. A controlled study. Am J Med 82: 772-780.

16. Chakravarty EF, Hubert HB, Lingala VB, Fries JF (2008) Reduced Disability and Mortality among Aging Runners: a 21-year Longitudinal Study. Arch Int Med 168: 1638-1646.

17. Felson DT, Niu J, Clancy M, Sack B, Aliabadi P, et al. (2007) Effect of recreational physical activities on the development of knee osteoarthritis in older adults of different weights: the Framingham Study. Arthritis Rheum 57: 6-12.
18. Williams PT (2013) Effects of Running and Walking on Osteoarthritis and Hip Replacement Risk. Med Sci Sports Exerc 45: 1292-1297.

19. Tran G, Smith TO, Grice A, Kingsbury SR, McCrory P, et al. (2016) Does sports participation (including level of performance and previous injury) increase risk of osteoarthritis? A systematic review and meta-analysis. $\mathrm{Br}$ J Sports Med 50: 1459-1466.

20. Lo GH, Driban JB, Kriska AM, McAlindon TE, Souza RB, et al. (2017) Is There an Association Between a History of Running and Symptomatic Knee Osteoarthritis? A Cross-Sectional Study from the Osteoarthritis Initiative. Arthritis Care Res (Hoboken) 69: 183-191.

21. Timmins KA, Leech RD, Batt ME, Edwards KL (2017) Running and Knee Osteoarthritis: A systematic review and Meta -analysis. Am J Sports Med 45: 1447-1457. 